\title{
Anterior fundoplication at the time of congenital diaphragmatic hernia repair
}

\author{
Yigit S. Guner · Steven Elliott · Clifford C. Marr • \\ Stephen K. Greenholz
}

Accepted: 18 June 2009/Published online: 4 July 2009

(C) The Author(s) 2009. This article is published with open access at Springerlink.com

\begin{abstract}
Purpose The loss of normal anatomic barriers in neonates with congenital diaphragmatic hernia $(\mathrm{CDH})$ can predispose children to gastroesophageal reflux (GER). In an attempt to improve post-operative feeding, we have added a modified anterior fundoplication to restore natural gastric and esophageal positioning.

Methods The institutional review board of both participating centers approved this study. Between 1997 and 2008, 13 neonates with high-risk anatomy underwent repair of $\mathrm{CDH}$ combined with an anterior fundoplication (BoixOchoa). The anatomic indications for concomitant fundoplication were absence of an intra-abdominal esophagus, an obtuse angle of His, and a small, vertically oriented stomach.

Results Ten patients survived to discharge and eight were on full oral nourishment. One required partial gastrostomy feedings for an improving oral aversion and quickly
\end{abstract}

Presented at the 41st Annual Pacific Association of Pediatric Surgeons Conference, Jackson Lake Lodge Wyoming, 30 June 2008.

Y. S. Guner · S. Elliott - C. C. Marr · S. K. Greenholz Department of General Surgery, University of California Davis Medical Center, Sacramento, CA 95817, USA

e-mail: yguner@chla.usc.edu

C. C. Marr · S. K. Greenholz

Department of Pediatric Surgery, University of California Davis

Medical Center, Sacramento, CA 95817, USA

C. C. Marr · S. K. Greenholz

Sutter-Memorial Medical Center, Sacramento, CA 95819, USA

S. K. Greenholz $(\bowtie)$

5275 F Street, Suite 3, Sacramento, CA 95819, USA

e-mail: Sgreenholz@aol.com progressed to full oral feedings. One patient with chromosomal anomalies and swallowing dysfunction remained on long-term bolus gastrostomy feedings. Two with progressive symptoms of GER and failure to thrive required conversion to a $360^{\circ}$ wrap after 18 months of medical management. This was performed in conjunction with a planned, staged muscle flap reconstruction in one patient. There were no complications related to the fundoplication. Conclusion Anatomic predictors of severe GER can be efficiently countered at the time of $\mathrm{CDH}$ repair. A modified fundoplication should be considered in the operative management of high-risk infants.

Keywords Reflux $\cdot$ Neonate $\cdot \mathrm{CDH} \cdot$ Fundoplication

\section{Introduction}

Gastroesophageal reflux is a common morbidity in survivors of congenital diaphragmatic hernia $(\mathrm{CDH})[1,2]$. When severe, it is associated with compromised growth and exacerbation of chronic lung disease [1, 2]. The reported incidence of GER ranges from 11 to $60 \%$ [1-5] and can be as high as $80 \%$ in the more severe cases, such as neonates requiring pre-operative extracorporeal membrane oxygenation (ECMO) [6]. Symptoms associated with reflux can be recalcitrant to medical management and necessitate non-oral nutrition techniques with continuous tube feedings. Surgical anti-reflux procedures are needed in $6-35 \%$ of the long-term survivors [1-5]. In an attempt to improve post-operative perinatal oral nourishment, we have added a modified anterior fundoplication to restore natural gastric and esophageal positioning. Here, we describe our experience and outcomes following this procedure. 


\section{Methods}

This study was approved by the institutional review board (IRB) of both the University of California Davis Medical Center and Sutter-Memorial Medical Center. We then performed retrospective chart reviews of all the neonates who underwent $\mathrm{CDH}$ repair and anterior fundoplication. All parents were given ample explanation as to the experimental nature of this additional procedure and all provided informed consent. We reviewed the subsequent clinical course with particular attention to feeding regimens. A single attending surgeon performed all of the cases.

\section{Patient selection}

The choice to perform concomitant anterior fundoplication was solely based on anatomic findings at the time of the $\mathrm{CDH}$ repair. The anatomic indications for anterior fundoplication were absence of an intra-abdominal esophagus, an obtuse angle of His, and a small and/or a vertically oriented stomach. These anatomic barriers to GER have been well described and detailed by Boix-Ochoa [7-10], as well as others [11-15] in the last three decades.

\section{Operative procedure}

A delayed surgical approach was utilized awaiting maximal resolution of pulmonary hypertension. We performed the anterior fundoplication following repair of the diaphragmatic defect. First, the esophagus was mobilized enough to ensure that a segment of esophagus was intraabdominal and the anterior two-thirds of the abdominal esophagus was sutured to the diaphragm hiatus. The fundus was then mobilized by division of the most superior short gastric vessels. The fundoplication was performed by suturing the fundus to the right lateral margin of the esophagus. This maneuver also creates an acute angle of His, which is further reinforced by the gastrophrenopexy (Fig. 1). Given that the crura are often weak in this population, the procedure was modified from previous descriptions [7, 15] by eliminating the crural dissection and approximation. This strategy also allowed for anterior wrap construction without the need for crural sutures in neonates with complete agenesis of the diaphragm. A Ladd procedure was performed as indicated. Gastrostomy tubes were not routinely placed. Empiric medical management of GER was followed post-operatively.

\section{Results}

Between May 1997 and February 2008, a single attending surgeon performed $32 \mathrm{CDH}$ repairs where 13 neonates

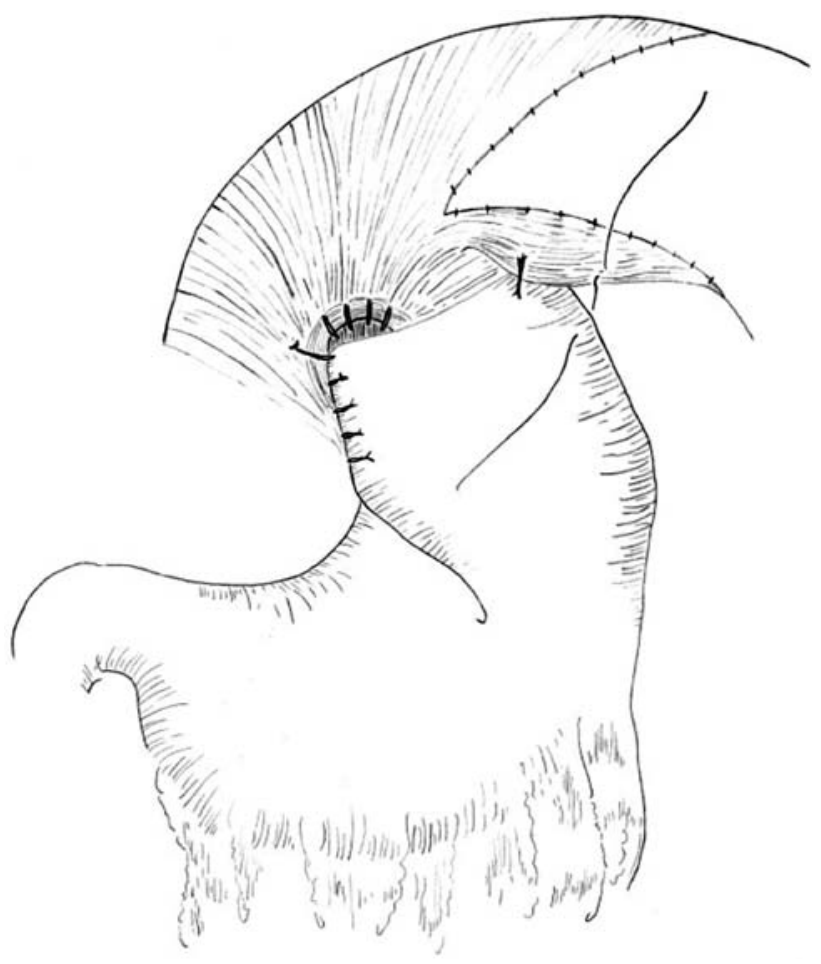

Fig. 1 Anterior fundoplication after a patch repair of the diaphragmatic hernia. Near the medial aspect of the patch, gastrophrenopexy is performed by approximating the fundus to the diaphragm with several interrupted sutures

exhibited relationships worrisome for severe post-operative GER and underwent concomitant anterior fundoplication.

The mean gestational age was 38.7 weeks (36-40 weeks), and birth weight was $3.2 \mathrm{~kg}(2.2-3.9 \mathrm{~kg})$. Average number of days to proceed to the operating room, consistent with maximal resolution of pulmonary hypertension, was 11 days (2-25 days). Two neonates required ECMO pre-operatively. Six neonates had large defects that required patch closure. There were no short-term complications related to the fundoplication prior to hospital discharge.

Of the 13 neonates, 10 survived to discharge. Two neonates expired due to irreversible fatal pulmonary hypoplasia, and one due to complex congenital heart disease. Outpatient follow-up for these neonates ranged from 2 to 12 years (median 8.5 years). Of the ten surviving infants, eight were discharged home on oral feedings, and one was discharged home on partial oral and gastrostomy bolus feedings due to oral aversion. This patient rapidly progressed to full oral feedings. Another infant was discharged on bolus gastrostomy feedings, in whom the gastrostomy was placed during $\mathrm{CDH}$ repair, due to the diagnosis of trisomy 18 and expectation of poor oral feeding abilities. Two patients had recurrent severe symptoms of reflux requiring conversion to a Nissen fundoplication at 18 months of age. In one, this was added at 
the time of a planned staged muscle flap replacement of the synthetic diaphragm, a procedure commonly performed at our institution [16] during exposure of the stomach via the chest. None of the patients have had recurrence of the diaphragmatic hernia or a hiatal hernia.

In addition, 19 neonates underwent only $\mathrm{CDH}$ repair, all via an abdominal approach, without undergoing a concomitant anterior fundoplication. These 19 neonates did not have anatomic findings associated with reflux. None required anti-reflux surgery later in life. In this group, four infants did not survive to hospital discharge.

\section{Discussion}

Significant GER can be an impediment to early establishment of full oral feedings. Nasogastric tubes and drip feedings as part of the medical management only complicate the establishment of eventual oral feedings. Included in the spectrum of defects associated with $\mathrm{CDH}$ are anatomic abnormalities of the esophagus and stomach predisposing to GER. These include a small, vertically oriented stomach, an obtuse angle of His and the lack of an intra-abdominal esophagus [4, 17]. Fundoplication performed at a later stage for recalcitrant symptoms is often difficult secondary to adhesions, the presence of a synthetic patch and abnormal positioning of the spleen and liver. Therefore, we elected to perform a low morbidity primary anti-reflux procedure to optimize early oral feedings and assist the management of GER in infants with high-risk anatomy [7-10, 15].

A $360^{\circ}$ gastric fundoplication may be difficult at the time of $\mathrm{CDH}$ repair due to insufficient fundus to wrap around the esophagus. We selected the Boix-Ochoa antireflux procedure for its principle of establishing normal anatomic barriers, the utility in infants with small stomachs $[7,15]$ and its relative ease, particularly without the crural dissection. In this population, the crura are often weak and fragile and dissection adds time and can increase the morbidity of the anti-reflux procedure, without improving GER. To date, none of the infants developed a hiatal hernia, supporting the decision to avoid crural dissection.

Data are lacking in literature regarding the use of antireflux procedures at the time of $\mathrm{CDH}$ repair and results were conflicting regarding factors that predict future development of GER. Kieffer et al. [9] reported the preoperative thoracic position of the stomach as a risk factor for GER. With the use of a multivariate model, Diamond et al. showed that the position of the liver within the chest and need for patch closure were positive predictors of future GER [18]. These reports are supportive of the concept of regional mediastinal development abnormalities in $\mathrm{CDH}$. Other investigators also found that infants undergoing patch repair have a greater likelihood of developing GER $[2,5]$. However, Koot et al. [3] could not demonstrate a positive relationship between the size of the defect and GER. Fashing et al. [19] could not show an association between GER and thoracic position of the stomach, abnormal position of the liver or the use of a patch.

Based on the above data, it is difficult to predict which infants are at high-risk for developing GER. Nevertheless, in recent reports, the most commonly reported association of GER after $\mathrm{CDH}$ repair is in infants with the severest form of pulmonary hypoplasia due to large defects [5, 17, 20]. In our series, the average day of life consistent with maximal resolution of pulmonary hypertension was 11 days, and two neonates required ECMO rescue prior to being stable for diaphragm repair. These neonates comprise a group with severe to moderate disease and would thus be expected to be at high risk for GER.

The anatomic criteria we used for patient selection for concomitant anterior fundoplication (absence of an intraabdominal esophagus, an obtuse angle of His and a small, and/or a vertically oriented stomach), although not specifically studied in a cohort of infants with $\mathrm{CDH}$, have been well documented and studied to be associated with GER [7, 9, 10, 15, 21-24]. DeMeester et al. were the first to indisputably demonstrate the need for having an adequate length of intra-abdominal esophagus to have an anti-reflux valvular effect $[21,22]$. When the angle of His is obtuse, it is converted into a funnel such that the stomach contents are easily directed to the esophagus. In 1986, Bardaji et al. [10] demonstrated with a series of in vivo experiments in dogs that only at very high intra-gastric pressures reflux occurs if the angle of His is acute. In addition, Thor et al. [24] demonstrated similar findings in human cadavers that an obtuse angle of His was associated with reflux. Recreation of the angle of His has also been described to be beneficial as part of Nissen fundoplication as well [23]. Finally, in the case of microgastria, a full fundoplication is not anatomically possible as there is an inadequate amount of fundus to wrap around the esophagus. In such cases, the Boix-Ochoa operation is well tolarated [15].

The final selection was determined by the anatomic criteria of loss of normal barriers to GER. The primary outcome of this study was discharge on oral feedings, which we were able to achieve in $8 / 10$ surviving neonates and one other infant was only on partial NG feedings due to oral aversion. The subsequent need for Nissen fundoplication was eventually seen in 2/10 infants. Of note, Nissen fundoplication was deferred for 18 months in both children, during which time oral feedings were possible. None of the neonates whom we deemed not to have high-risk anatomy required anti-reflux surgery later in life, suggesting that our anatomic selection criteria have merit. After 
including these 15 surviving neonates who did not undergo anterior fundoplication, the incidence of conversion to Nissen is only $2 / 25(8 \%)$ in our population.

Our non-randomized experience performing a previously unreported combination of anterior fundoplication and $\mathrm{CDH}$ repair allows us to conclude that an anterior fundoplication to restore anatomy can be quick and without morbidity [7, 15]. In addition, anterior fundoplication appears to improve post-operative oral feeding. A modified fundoplication should therefore be considered in the operative management of high-risk infants. Future randomized trials may be conducted to determine the efficacy of this procedure.

Open Access This article is distributed under the terms of the Creative Commons Attribution Noncommercial License which permits any noncommercial use, distribution, and reproduction in any medium, provided the original author(s) and source are credited.

\section{References}

1. Stolar CJ, Levy JP, Dillon PW, Reyes C, Belamarich P, Berdon WE (1990) Anatomic and functional abnormalities of the esophagus in infants surviving congenital diaphragmatic hernia. Am J Surg 159:204-207

2. Muratore CS, Utter S, Jaksic T, Lund DP, Wilson JM (2001) Nutritional morbidity in survivors of congenital diaphragmatic hernia. J Pediatr Surg 36:1171-1176

3. Koot VC, Bergmeijer JH, Bos AP, Molenaar JC (1993) Incidence and management of gastroesophageal reflux after repair of congenital diaphragmatic hernia. J Pediatr Surg 28:48-52

4. Nagaya M, Akatsuka H, Kato J (1994) Gastroesophageal reflux occurring after repair of congenital diaphragmatic hernia. J Pediatr Surg 29:1447-1451

5. Su W, Berry M, Puligandla PS, Aspirot A, Flageole H, Laberge JM (2007) Predictors of gastroesophageal reflux in neonates with congenital diaphragmatic hernia. J Pediatr Surg 42:1639-1643

6. D'Agostino JA, Bernbaum JC, Gerdes M et al (1995) Outcome for infants with congenital diaphragmatic hernia requiring extracorporeal membrane oxygenation: the first year. J Pediatr Surg 30:10-15

7. Boix-Ochoa J (1986) The physiologic approach to the management of gastric esophageal reflux. J Pediatr Surg 21:1032-1039

8. Boix-Ochoa J, Rowe M (1998) Gastroesophageal reflux. MosbyYear Book, St Louis

9. Boix-Ochoa J, Casasa Carbo JM (1977) Pathology of the cardiohiatal sector. An Esp Pediatr 10:597-604
10. Bardaji CB-OJ (1986) Contribution of the His angle to the gastroesophageal antireflux mechanisms. Pediatr Surg Int 1:172-176

11. Subramaniam R, Dickson AP (2000) Long-term outcome of Boix-Ochoa and Nissen fundoplication in normal and neurologically impaired children. J Pediatr Surg 35:1214-1216

12. Hernandez-Orgaz A, Lopez-Alonso M (2004) Surgical treatment of the GER with Boix-Ochoa technique: long-term results. Cir Pediatr 17:122-124

13. Numanoglu A, Millar AJ, Brown RA, Rode H (2005) Gastroesophageal reflux strictures in children, management and outcome. Pediatr Surg Int 21:631-634

14. Briganti V, Oriolo L, Calisti A (2003) Reflux strictures of the oesophagus in children: personal experience with preoperative dilatation followed by anterior funduplication. Pediatr Surg Int 19:544-547

15. Greenholz SK, Hall R, Lilly JR (1989) The Boix-Ochoa antireflux operation in infants with small stomachs. Surg Gynecol Obstet 168:357-358

16. Lee SL, Poulos ND, Greenholz SK (2002) Staged reconstruction of large congenital diaphragmatic defects with synthetic patch followed by reverse latissimus dorsi muscle. J Pediatr Surg 37:367-370

17. Kieffer J, Sapin E, Berg A, Beaudoin S, Bargy F, Helardot PG (1995) Gastroesophageal reflux after repair of congenital diaphragmatic hernia. J Pediatr Surg 30:1330-1333

18. Diamond IR, Mah K, Kim PC, Bohn D, Gerstle JT, Wales PW (2007) Predicting the need for fundoplication at the time of congenital diaphragmatic hernia repair. J Pediatr Surg 42:10661070

19. Fasching G, Huber A, Uray E, Sorantin E, Lindbichler F, Mayr J (2000) Gastroesophageal reflux and diaphragmatic motility after repair of congenital diaphragmatic hernia. Eur J Pediatr Surg 10:360-364

20. Kamiyama M, Kawahara H, Okuyama H et al (2002) Gastroesophageal reflux after repair of congenital diaphragmatic hernia. J Pediatr Surg 37:1681-1684

21. DeMeester TR, Wernly JA, Bryant GH, Little AG, Skinner DB (1979) Clinical and in vitro analysis of determinants of gastroesophageal competence: a study of the principles of antireflux surgery. Am J Surg 137:39-46

22. Bonavina L, Evander A, DeMeester TR et al (1986) Length of the distal esophageal sphincter and competency of the cardia. Am J Surg 151:25-34

23. Robie DK, Pearl RH (1991) Modified Nissen fundoplication: improved results in high-risk children. J Pediatr Surg 26:12681272

24. Thor KB, Hill LD, Mercer DD, Kozarek RD (1987) Reappraisal of the flap valve mechanism in the gastroesophageal junction. a study of a new valvuloplasty procedure in cadavers. Acta Chir Scand 153:25-28 